\title{
Экранированные и безэховые камеры как альтернативные измерительные площадки и средства защиты информации
}

А. Скребнев ${ }^{1}$

УДК 621.391 | ВАК 05.11 .01

\begin{abstract}
Компания "ТЕСТПРИБОР" производит экранированные и безэховые камеры TЕКО, отвечающие требованиям ФСТЭК России, а также ГОСТ в области радиоизмерений и электромагнитной совместимости. Накопленный опыт разработки и производства позволяет компании предлагать максимально эффективные с точки зрения качества и стоимости решения, полностью соответствующие нормативным документам и пожеланиям заказчика.
\end{abstract}

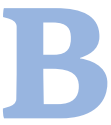

ыбор средств технической защиты информации (ТЗИ) от утечек по различным каналам требует тщательного подхода, учитывающего тонкости всех руководящих документов, а также специфики применения того или иного устройства, участвующего в обработке защищаемой информации. Однако не менее трудоемкой и важной является задача по оснащению лабораторий защиты информации обязательным оборудованием, в полной мере соответствующим требованиям нормативной документации и при этом доступным с точки зрения бюджета организации. Если в случае поиска средств ТЗИ можно полагаться на реестры и сертификаты, то при поиске испытательного и измерительного оборудования такая возможность отсутствует. Это означает, что для правильного выбора необходим подробный анализ доступных на рынке решений, детальное изучение характеристик и особенностей.

Одной из наиболее проблематичных областей Тзи с точки зрения технического обеспечения является защита от побочных электромагнитных излучений и наводок (ПЭМИН). В частности, большого внимания требует проблема создания недорогих экранированных объемов (камер), а также обустройства альтернативных измерительных площадок (АИП), что связано как с техническими особенностями (в первую очередь размерами и невозможностью перемещения конструкции), так и с финансовой составляющей.

Компания «ТЕСТПРИБОР» уже несколько лет производит экранированные (ЭК) и безэховые (БЭК) камеры ТЕКО, отвечающие требованиям ФСТЭК России, а также ГОСТ в области радиоизмерений и электромагнитной совместимости (ЭМС). Накопленный опыт разработки и производства позволяет компании предлагать максимально эффективные с точки зрения качества и стоимости

АО «ТЕСТПРИБОР», технический специалист, skrebnev@test-expert.ru. решения, полностью соответствующие нормативным документам и пожеланиям заказчика.

\section{ЭКРАНИРОВАННЫЕ КАМЕРЫ}

Одним из решений для ПД ИТР (противодействия иностранным техническим разведкам), гарантирующим защиту информации от утечек за счет ПЭМИН, могут служить ЭК.

Изделия представляют собой самонесущую сборную конструкцию из стальных панелей толщиной 2 мм, соединенных между собой болтами. Для герметизации соединений используется специальная проводящая сетчатая прокладка. Такая технология позволяет разобрать камеру без применения специальных инструментов и переместить ее в случае необходимости.

Основным достоинством ЭК ТЕКО (рис. 1) является их соответствие I классу по ГОСТ Р 50414-92,

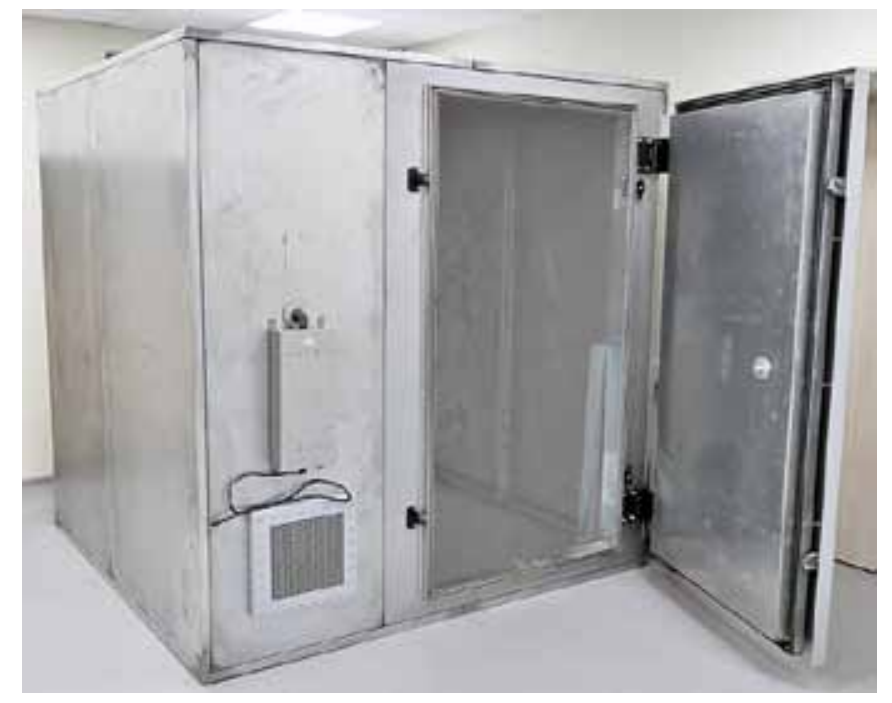

Рис. 1. Экранированная камера ТЕКО 


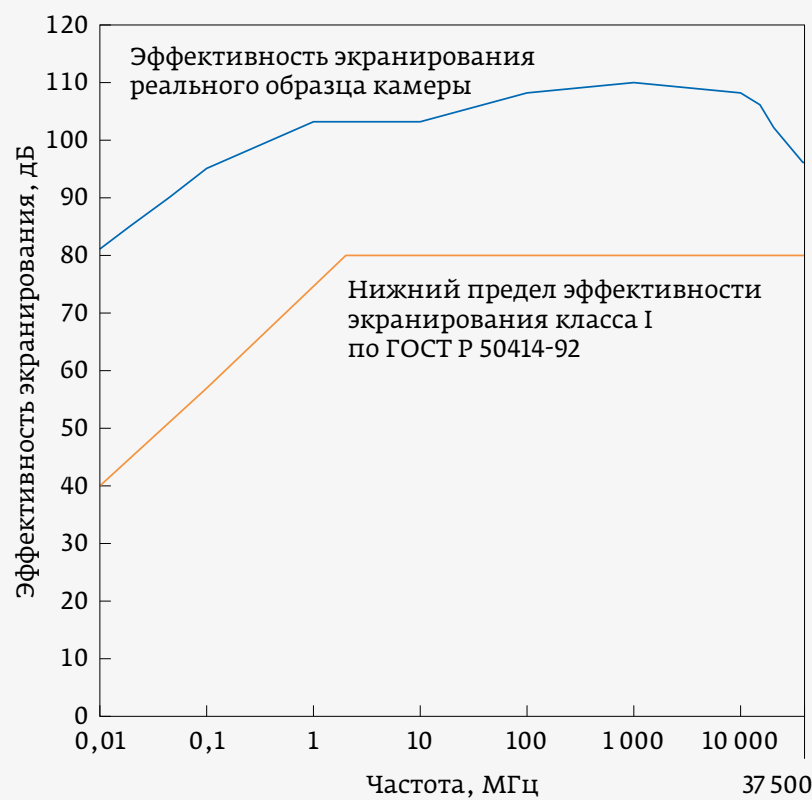

Рис. 2. Зависимость эффективности экранирования от частоты

устанавливающему требования к экранированию. График зависимости эффективности экранирования реального образца камеры от частоты представлен на рис. 2. Стоит отметить, что при наличии соответствующих требований эффективность экранирования может превышать 120 дБ.

Компанией "ТЕСТПРИБОР» разработаны и освоены в производстве различные комплектующие, также соответствующие классу I по ГОСТ Р 50414-92. Экранированные двери (рис. 3) отличаются надежным подвесом на 2-х, 3-х или 4-х усиленных петлях, оригинальной запирающей системой, обеспечивающей параллельный прижим двери к плоскости рамы.

Количество рядов экранирующих бериллиевых пружин может меняться в зависимости от конфигурации камеры и требуемыххарактеристик. Помимо стандартного

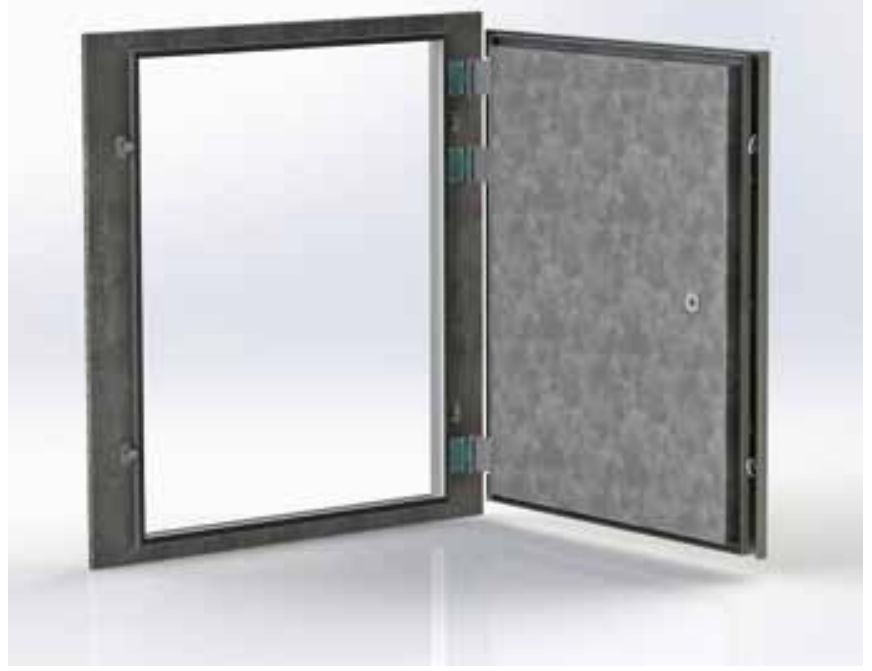

Рис. 3. Экранированная дверь

ручного механизма закрывания, может быть предусмотрен автоматический/полуавтоматический, а также установлена система контроля доступа.

Воздуховодные фильтры (рис. 4) гарантируют защиту от проникновения электромагнитных полей через вентиляцию. Они состоят из решетки с сотовой структурой, работающей по принципу запредельного волновода, и фланца для непосредственного соединения с воздуховодом. Размеры фильтров, а также диаметр ячейки могут варьироваться в зависимости от требований.

Для ввода в камеру кабелей электропитания больших сечений могут применяться дробно-засыпные фильтры (рис. 5). Экран кабеля с предварительно удаленной внешней изоляцией засыпается металлической дробью, электрически связанной с экраном камеры, в результате предотвращается передача помех.

В стандартную комплектацию камер ТЕКО также входят сетевые помехоподавляющие фильтры (рис. 6), рассчитанные на напряжение как переменного, так и постоянного тока.

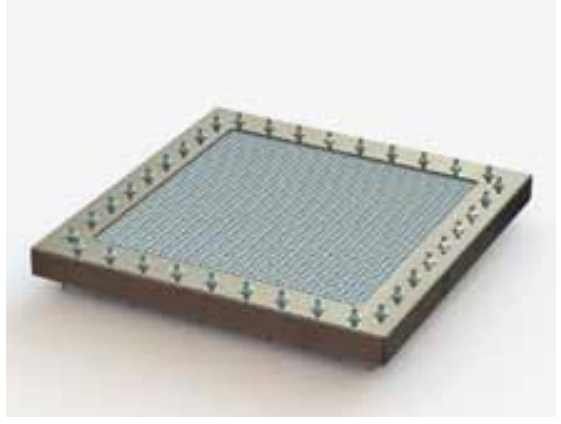

Рис. 4. Воздуховодный фильтр

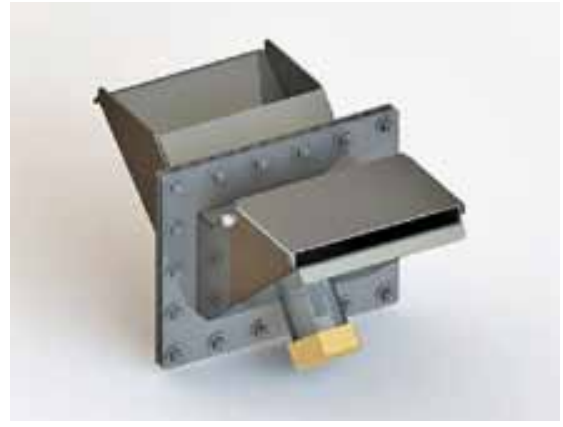

Рис. 5. Дробно-засыпной фильтр

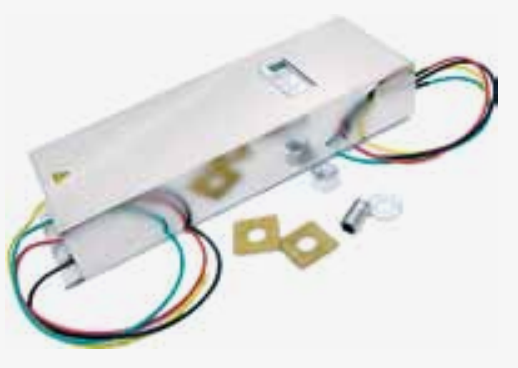

Рис. 6. Сетевой помехоподавляющий фильтр ТЕКО ФП-2-250 


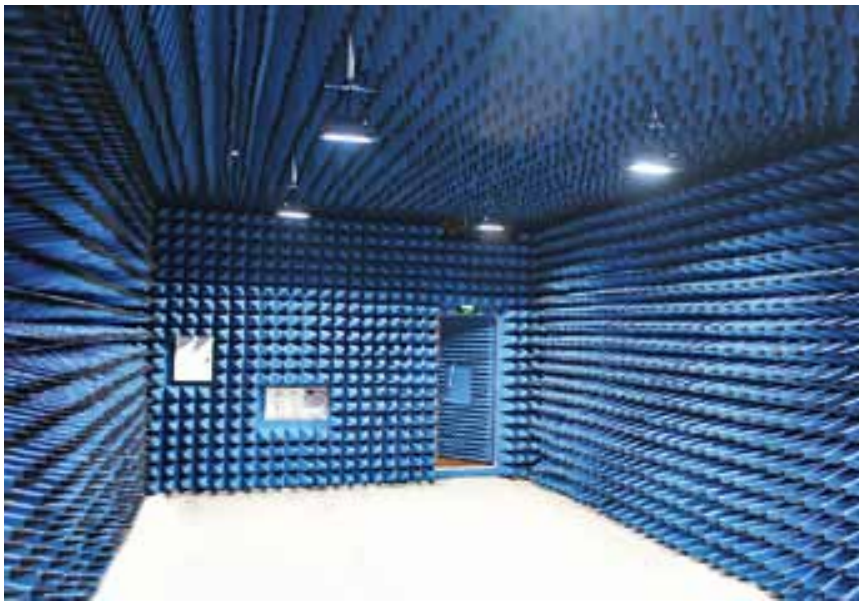

Рис. 7. АИП для исследований ПЭМИН на базе БЭК ТЕКО

Доступны модели, рассчитанные на работу в трехфазных сетях с напряжением до 400 В и в сетях с частотой напряжения 400 Гц.

\section{БЕЗЭХОВЫЕ КАМЕРЫ}

БЭК ТЕКО обеспечивают полное соответствие нормативным документам в области специсследований ТС, ЭМс и антенных измерений. В зависимости от назначения наполнение камер и их характеристики варьируются.

Так, например, БЭК в качестве АИП для проведения исследований ПЭМИН (рис. 7) имеет покрытие внутренних стен и потолка комбинированным радиопоглощающим материалом (рис. 8), состоящим из ферритовых плиток и пирамидального поглотителя ТЕКО РП-500С.

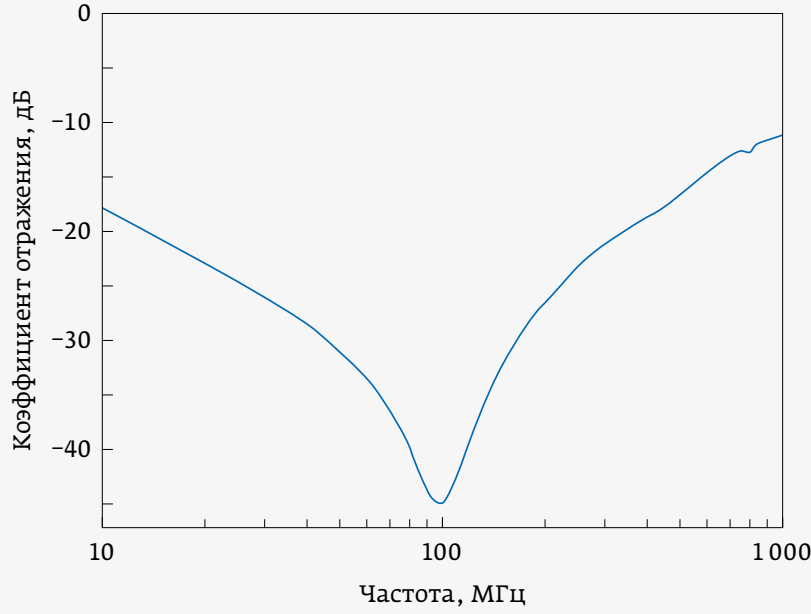

Рис. 9. Коэффициент отражения ферритового поглотителя

Характеристики ферритового поглотителя приведены на рис. 9, пирамидального - в табл. 1. ТЕКО РП является трудногорючим (группа горючести Г1), негигроскопичным и имеет максимальную рассеиваемую мощность $1500 \mathrm{BT} / \mathrm{M}^{2}$.

При разработке проекта БЭК в качестве АИП для исследований ПЭМИН особое внимание необходимо уделять соответствию затухания электромагнитных волн гОСТ Р 51320-99. Один лишь пирамидальный материал при размерах типовой БЭК (ориентировочно 9×6×6 м) не способен обеспечить отклонение затухания от теоретического менее 4 дБ в частотном диапазоне от 30 до 1000 МГц,

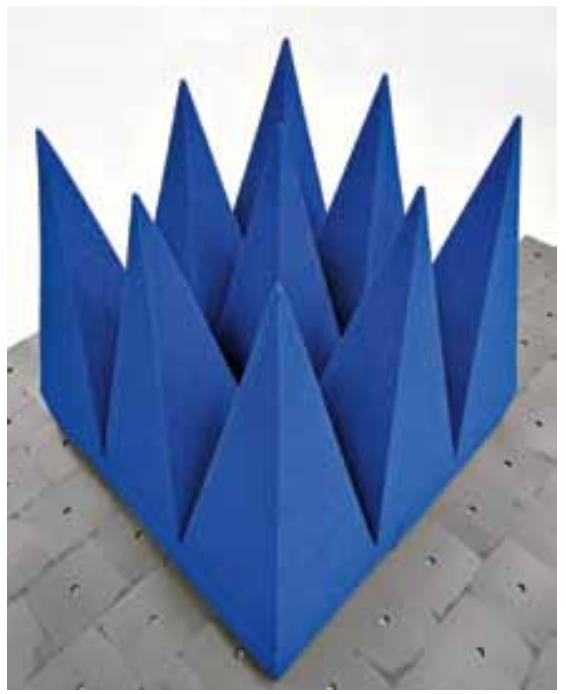

Рис. 8. Комбинированный радиопоглощающий материал (ферритовый и пирамидальный)
Таблица 1. Коэффициент отражения некоторых типов РПМ ТЕКО РП

\begin{tabular}{ccccc} 
Частота & \multicolumn{4}{c}{ Коэффициент отражения при нормальном падении, дБ } \\
\cline { 2 - 5 } & РП-200 & РП-400 & РП-500 & $\begin{array}{c}\text { РП-500с совместно } \\
\text { с ферритовым поглотителем }\end{array}$ \\
\cline { 2 - 5 } 100 & -3 & -4 & -5 & -16 \\
\hline 200 & -6 & -10 & -17 & -17 \\
\hline 400 & -15 & -23 & -28 & -17 \\
\hline 700 & -24 & -29 & -36 & -19 \\
\hline 1500 & -31 & -38 & -42 & -20 \\
\hline 3000 & -40 & -43 & -45 & -22 \\
\hline 6000 & -45 & -51 & -53 & -23 \\
\hline 10000 & -49 & -58 & -61 & -26 \\
\hline
\end{tabular}




\section{ИСПЫТАТЕАЬНЫЕ KAMEPЫ TEKO}

\section{от эксперта в испытаниях на ЭМС}

\section{ТЕСТПРИБОР}

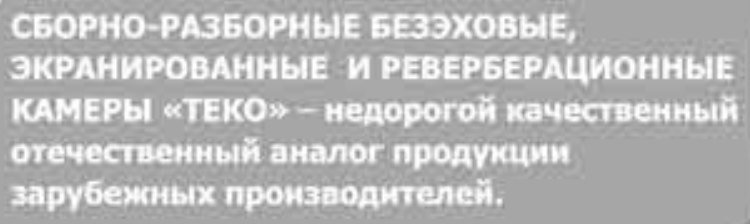

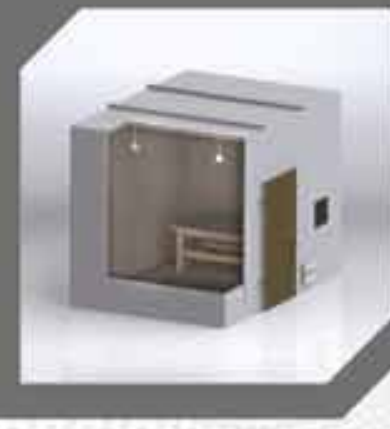

ЭКРАНИРОВAHНGIE KAMEPG

- диапазон рабочих частот:

- диапазон рабочих частот: от 10 кГц до 40 ПТц

- размер: любой по требованию заказчика

- класс экранирования: I no ГOCT P 50414-92
- класс экранирования: I no roct P $50414-92$

- измерительные расстояния: $3,5,10 \mathrm{M}$

- cootветствие ГОСТ СИСПР 16-1-4
БЕ $3 \ni X 0 B \mathrm{LIE}$

(ก0^УБอコอХอยแล) KAMEPGI от 10 кГц до 40 ГТц

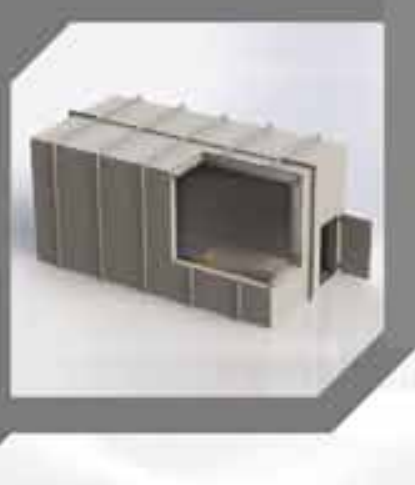

.

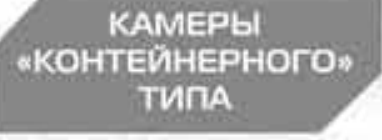

- диапазон рабочих частот: от 10 кГц до 40 ГТ

- размер: любой по требованию заказчика

- класс экранирования: I no ГOCT P 50414-92

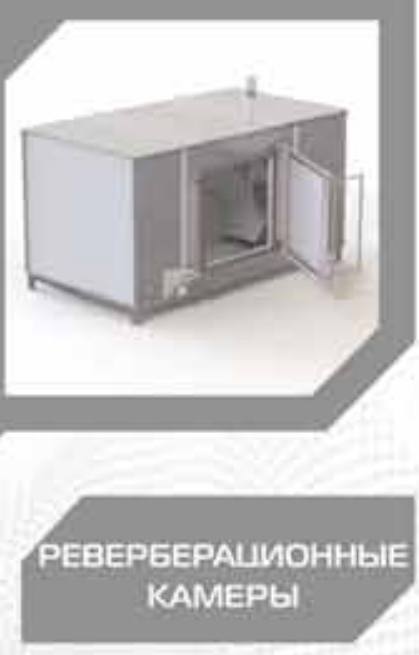

- диапазон рабочих частот: от 200 МГц до 40 ПТц

- размер: любой по требованию заказчика

- положение отражателя контролируется с ПК

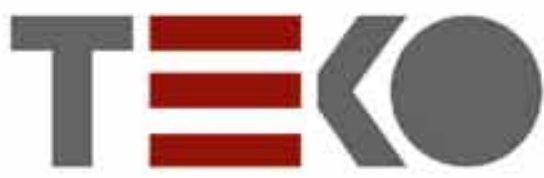

ПРИ РАЗРАБОТКЕ И ИЗГОТОВЛЕНИИ КАМЕР ИСПОЛЬЗОВАН ПОДХОД, подразумевающий использование опробованных готовых модулей, типовых панелей и комплектующих. 

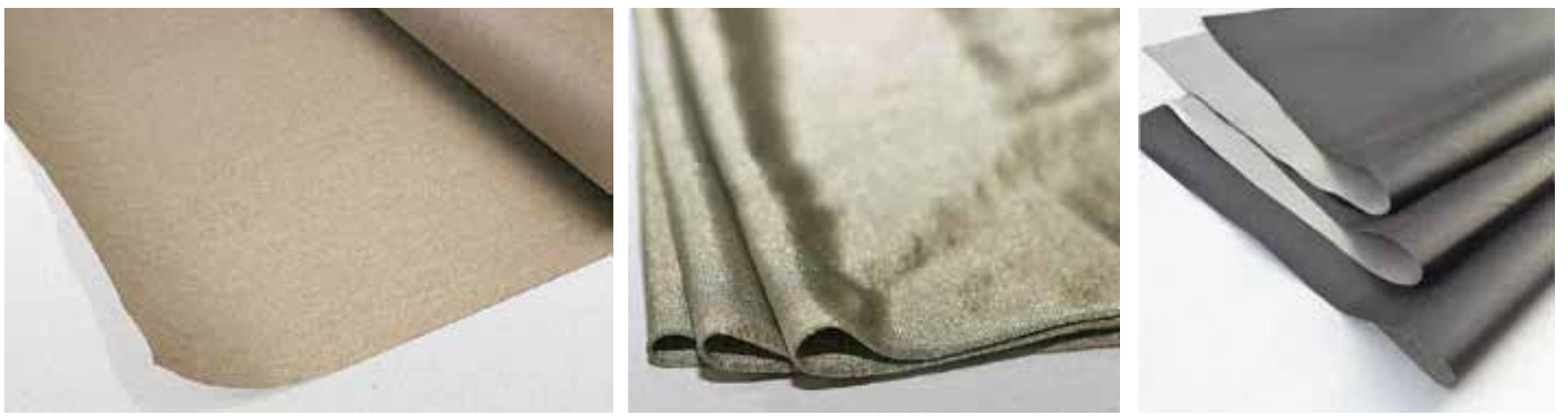

Рис. 10. Экранирующие ткани Aaronia и ТЕКО ТЭМП

как того требует ГОСт. В связи с этим дополнительно применяется ферритовый материал в виде плиток толщиной несколько миллиметров, который, в отличие от пирамидального, наиболее эффективен на частотах до 1000 МГц.

Компанией "ТЕСТПРИБОР» также разработана универсальная БЭК как АИП для исследований ПЭМИН, АЭП и ВЧО. Главной отличительной особенностью универсальной БЭК является то, что в качестве звукопоглощающего материала на стенах и потолке используется радиопоглощающий ТЕКО РП. Пенополиуретан, на основе которого он изготовлен, обладает отличным коэффициентом звукопоглощения, что подтверждено испытаниями в специализированной акустической лаборатории. Это позволяет отказаться от применения дополнительных звукопоглощающих материалов (за исключением укладываемого на пол) и лишних конструкций внутри БЭК, а главное - полностью сохранить уровень затухания электромагнитных волн в соответствии с ГОСТ Р 51320-99.

В качестве опций в БЭК могут устанавливаться:

- поворотный стол;

- антенная мачта;

- система вентиляции и кондиционирования;

- система видеонаблюдения;

- прочие системы связи, контроля.

\section{МАТЕРИАЛЫ И ЭЛЕМЕНТЫ АЛЬТЕРНАТИВНЫХ ЭКРАНОВ}

В некоторых случаях более целесообразным является создание временных или мобильных экранированных объемов, позволяющих с меньшими затратами получить защиту от проникновения электромагнитного поля. Эффективность экранов такого типа ниже, чем у металлических камер, однако за счет простоты монтажа и низкой стоимости они могут стать оптимальным решением .

Основными элементами экранов альтернативной конструкции могут быть:

- экранирующие ткани;

- экранирующие прокладки;

- экранированные стекла или пленки.

Компания «ТЕСТПРИБОР» поставляет различные типы комплектующих для создания экранированных объемов. Экранирующие ткани Aaronia и ТЕКО ТЭМП (рис. 10) могут иметь разные состав (например, полиэстер / медь или нейлон / серебро) и толщину, что влияет на механические и электрические характеристики (табл. 2).

Ткани могут быть использованы для экранов как каркасной конструкции, так и для конструкций, использующих стены помещения или корпуса оборудования. Важным условием гарантии заявленной эффективности экранов любого типа является устранение всех отверстий и щелей, а также надежное заземление.

Таблица 2. Характеристики некоторых экранирующих тканей

\begin{tabular}{|c|c|c|c|}
\hline & Aaronia X-Dream & ТЕКО ТЭМП-МП-80 & ТЕКО ТЭМП-СН \\
\hline Диапазон частот & 100 МГц - 18 ГГц & 100 МГц - 10 ГГц & 100 МГц - 10 ГГц \\
\hline Эффективность экранирования & До 120 дБ & До 70 дБ & До 65 дБ \\
\hline Материал & Полиэстер/медь & Полиэстер / медь / никель & Нейлон / серебро \\
\hline Плотность & $130 \Gamma / M^{2}$ & $80 \Gamma / M^{2}$ & $100 \Gamma / M^{2}$ \\
\hline Толщина & $0,5 \mathrm{MM}$ & $0,08 \mathrm{MM}$ & $0,28 \mathrm{MM}$ \\
\hline
\end{tabular}


Проводящие прокладки позволяют герметизировать соединения любых элементов и частей экранов. Материал, профиль и размеры прокладок выбираются исходя из конструктивных особенностей конкретного изделия. Например, для уплотнения дверного проема в экранах II и III класса по ГОСТ Р 50414-92 (до 80 дБ) оптимальным является применение D-образной прокладки с металлической оболочкой и наполнителем из пены. Соединения стенок шкафов для оборудования могут быть защищены сетчатыми прокладками круглой или прямоугольной формы по аналогии с полноценными ЭК.
В случаях, когда необходим визуальный контроль экранированного объема, применяются специализированные окна. Они представляют собой сэндвич-структуру из двух слоев закаленного стекла, между которыми располагается прозрачная проводящая сетка. Эффективность экранирования окон, как правило, обратно пропорциональна их светопропусканию. Стоит отметить, что подобные стекла могут также применяться для защиты от утечки информации при работе с техническими средствами, имеющими дисплеи, в том числе персональными компьютерами и офисной техникой.

\section{КНИГИ ИЗДАТЕЛЬСТВА "ТЕХНОСФЕРА»}

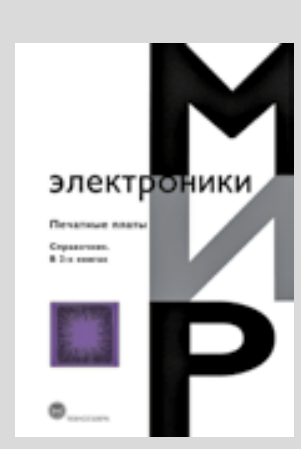

Цена 2600 руб. за два тома
ПЕЧАТНЫЕ ПЛАТЫ. СПРАВОЧНИК

\section{В 2-Х КНИГАХ}

\author{
Под ред. К. Кумбза
}

В издании рассматриваются все процессы создания и применения печатных плат: проектирование и выбор базовых материалов, изготовление, обеспечение качества и оценки надежности печатных плат и печатных узлов, монтаж плат, включая особенности бессвинцовых технологий пайки, а также методы и средства испытаний применительно к специальным требованиям. Шестое издание дополнено информацией по ценообразованию, количественной оценке технологичности плат, управлению производством и решению экологических проблем.

Все изменения в технологии изготовления печатных плат нашли свое отражение в этой книге, что привело к тому, что более 75\% ее глав были либо исправлены, либо являются новыми, свидетельствуя, что шестое издание содержит самую последнюю информацию.

Цель книги состоит в том, чтобы предоставить нужную информацию насколько возможно в более конкретном и подробном виде, используя промышленные стандарты там, где они существуют, и передовой опыт, имеющий технологическое обоснование и продемонстрировавший свою работоспособность там, где соответствующих стандартов нет

Справочник рассчитан на широкий круг специалистов-технологов, конструкторов, схемотехников и специалистов по надежности, поскольку печатные платы являются фундаментом проектирования и производства изделий электроники.

Данная книга может служить учебным пособием для студентов и аспирантов вузов соответствующих специальностей. 